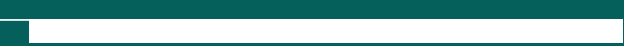

SECCIÓN: Problemas espaciales contemporáneos
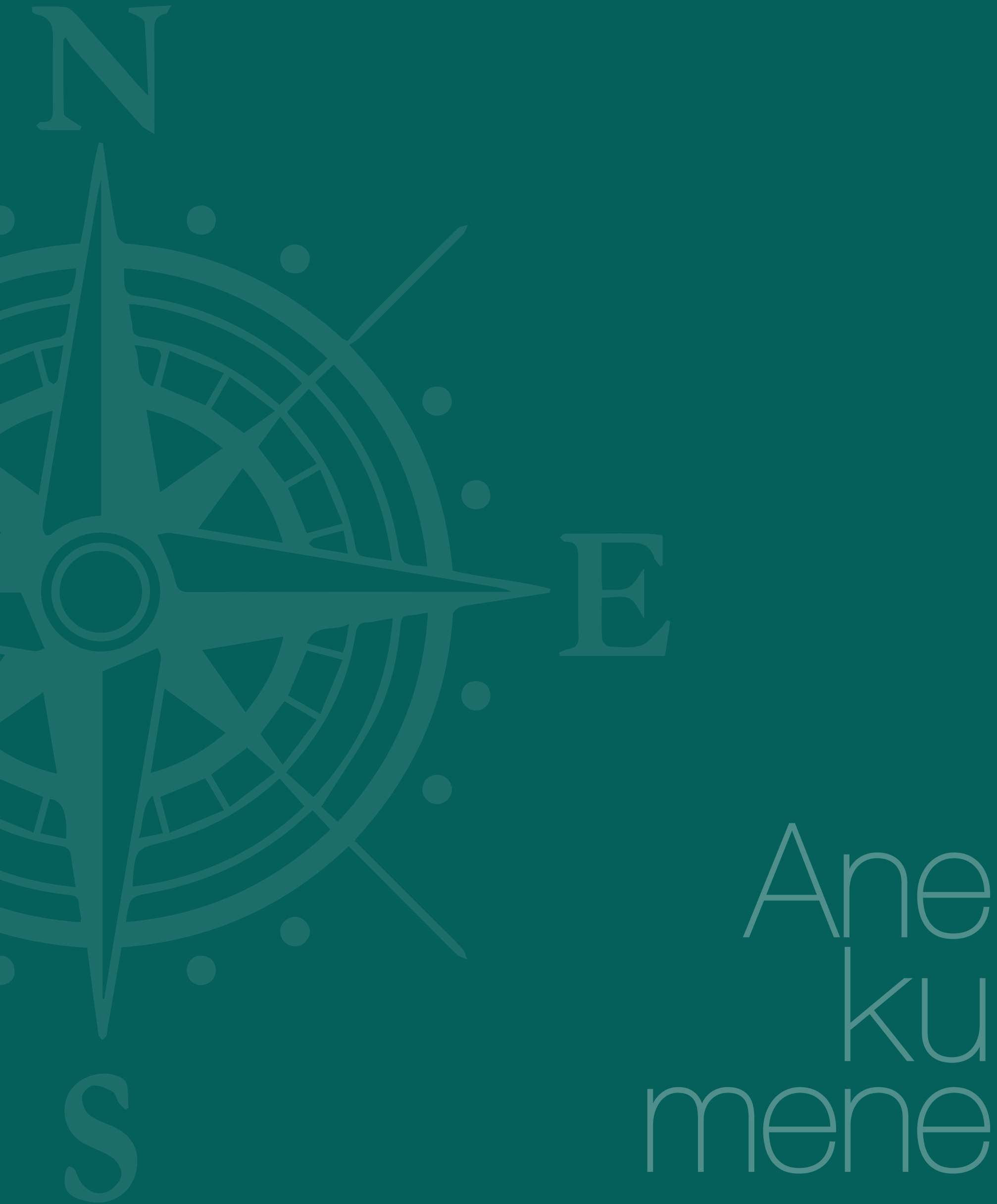


\section{Fontibón y su espacio comercial, una evolución en proceso}

\section{Fontibón and its Commercial Space: Evolution in Process Fontibón e seu espaço comercial, uma evolução em proceso}

René Alberto Martínez Cruz*

\begin{abstract}
Resumen
El espacio comercial de Fontibón está sometido a dos vertientes del desarrollo urbano que responden a lógicas distintas: el sector comercial que se proyecta desde el centro fundacional de Fontibón correspondiente al circuito comercial tradicional, con una larga historia y un pasado que aún puede verse reflejado en la evolución morfológica de las manzanas de este sector de la localidad, contrastado con los espacios globalizados que se han venido instalando en lo corrido del siglo $X X$ que se concentran en el intercambio internacional y en las operaciones no limitadas a un entorno económico encerrado. Ambos espacios comerciales se desarrollan de forma aislada e independiente, $y$ tienen mecanismos propios para adaptarse o adaptar el territorio a sus intereses económicos; sin embargo, la brecha de capital y de apoyo estatal entre ambas es notable en favor del gran capital del espacio globalizado.
\end{abstract}

\section{Palabras clave}

morfología; circuito comercial tradicional; espacio globalizado.

* Universidad Distrital Francisco José de Caldas. 


\section{Abstract}

The commercial space of Fontibón is subject to two aspects of urban development responding to different logics: the commercial sector projected from the foundation center of Fontibón, which corresponds to the traditional commercial circuit, with a long history and a past that can still be seen in the morphological evolution of the blocks of this sector of the locality, contrasted with the globalized spaces installed over the course of the twentieth century, which focus on international trade and on operations not limited to an enclosed economic environment. Both commercial spaces are developed in an isolated and independent manner, and they have their own mechanism to adjust or adapt the territory to their economic interests; however, the capital and state support gap between the two is notably in favor of the great capital of the globalized space.

\section{Keywords}

morphology; traditional commercial circuit; globalized space.

\section{Resumo}

O espaço comercial de Fontibón está submetido a duas vertentes do desenvolvimento urbano que respondem a lógicas diferentes: o setor comercial, que se projeta desde o centro fundacional da localidade de Fontibón, correspondente ao circuito tradicional, com uma longa história e um passado que ainda é possível ver refletido na evolução morfológica dos blocos desse setor da localidade, em contraste com os espaços globalizados que se tem instalado no percurso do século XX, que se concentram no intercâmbio internacional e nas operações não limitadas a um entorno econômico fechado. Os dois espaços comerciais se desenvolvem de forma isolada e independente, assim mesmo, têm mecanismos próprios para se adaptar ou adaptar o território aos seus interesses económicos. Porém, a disparidade de capital e de apoio estadual entre as duas é notável a favor do grande capital do espaço globalizado.

\section{Palavras-chave}

morfologia; circuito comercial tradicional; espaço globalizado. 


\section{Orígenes de Fontibón}

La historia de Fontibón se remonta al período prehispánico, habitada por los hontibones del que proviene su nombre. El patrón de poblados dispersos, muy común en la abana de Bogotá, muestra que sus inicios la ciudad no existía, como en las culturas maya, azteca e inca, sin embargo, tenían procesos culturales de concentración, como las celebraciones en torno a las ceremonias de correr la tierra, que consistía que un grupo de corredores de cada poblado competían en carrera hacia las lagunas sagradas del altiplano; otras prácticas eran el empalamiento ritual llamado como la gavia en la que los jóvenes chamanes eran bañados en la sangre de las víctimas.

Estos rituales a la llegada de los españoles fueron un conjunto de prácticas que mostraban una resistencia cultural formidable, distinta a la poca resistencia militar que impusieron al arribo de los españoles. Los frailes y doctrineros se quejaban de las idolatrías persistentes de los hontibones, sus santuarios ocultos en los bosques, sus carnavales, ceremonias, el correr la tierra y cánticos, preocupaba a los religiosos, por lo que solo hasta el siglo XVII, con los jesuitas, fue posible acabar con estas prácticas. Sin embargo, la aculturación más efectiva fue la espacial. Brewer-Carías (2006) afirma que la aculturación más eficiente fue la de instalar en los denominados pueblos de indios a los habitantes de la sabana de Bogotá , en particular a los indígenas Muiscas , y, a su vez, Garavaglia y Marchena (2005) sostienen que permitía disponer de la mano de obra indígena, como un hecho de coacción, pues los antiguos poblados eran incendiados. La trama ortogonal fue la más utilizada para las ciudades de los blancos y los pueblos indígenas como Fontibón, por su sencillez, funcionalidad y adaptabilidad al terreno (Brewer-Carías, 2006), además de ser fácil de elaborar y delimitar las distintas propiedades con el uso del cordel.

La ubicación de Fontibón le permitió ser un lugar de paso para los viajeros provenientes del tortuoso ascenso desde Honda; la casa del pueblo (hoy casa de la cultura) era el lugar donde se resguardaban. Su importancia estratégica y la fertilidad para los cultivos provocó que varios encomenderos se enfrentaran por integrarla a su propiedad, sin embargo, la administración la integró como Pueblo de la Real Corona (Velandia, 1983).

Esta situación permanecería hasta 1861, cuando, alegando que la población en su mayoría no era indígena, fue disuelto el resguardo y las tierras fueron repartidas a las haciendas aledañas, todo dentro del proceso de desamortización bajo el gobierno de Mosquera. Fontibón pasaría a ser un municipio aledaño a la capital, con una actividad agrícola importante en las haciendas dedicadas a la actividad ganadera lechera, cultivo de trigo y maíz.

Su historia como municipio culminaría en 1954, cuando en una decisión autoritaria el gobierno de Rojas Pinilla obligó la conurbación de
Fontibón junto con los municipios aledaños a la capital: Bosa, Suba, Usaquén, Usme y Engativá. Luego del derrocamiento del régimen, un grupo de vecinos intentó la separación de nuevo, sin embargo, no prosperó porque en su mayoría estaban de acuerdo con este proceso por los nuevos servicios que ahora recibían de la ciudad, mientras que los vecinos interesados en la separación tenían intereses particulares con la alcaldía municipal (Velandia, 1983).

\section{Evolución del centro: convergencia del pasado y del presente del barrio}

La evolución del entramado se aceleró con este proceso de anexión. Como es natural, nuevos barrios fueron construidos, sin embargo, conservaron las vías demarcadas por el entramado ortogonal del municipio y constituyeron una proyección de este hacia las zonas con menor densidad de población. La trama ortogonal implementada en las construcciones coloniales tiene en su centro un parque o plaza central y los edificios administrativos del municipio, en el caso de Fontibón son la alcaldía, la iglesia, la estación de bomberos, el cabildo y la casa de la cultura. Desde este centro se proyecta la trama con edificios residenciales y comerciales; adicionalmente, muchos caminos actuales tuvieron como origen los antiguos camellones donde transitaba el ganado, como el camellón de Anuncibay, parte de la actual diagonal 16 o Avenida Centenario.

Para la investigación que originó este artículo se analizó una zona en particular, la calle 18 entre carreras 100 y 116 en sentido sur norte, que se proyecta desde el centro fundacional y en la cual se puede observar la evolución morfológica del barrio, tal y como se observa en el mapa 1. La división de las manzanas para el análisis se realizó por medio de generaciones, es decir por construcción. En el mapa 1 la primera generación son las manzanas en cian, la segunda generación las manzanas en naranja y la tercera generación las manzanas en rojo.

Las manzanas iban siendo construidas de forma más compacta a medida que avanzaba el siglo XX y la demanda de casas se incrementaba. Las casas municipales construidas antes de 1950 (algunas se remontan al siglo XIX) eran de tamaño considerable (en cian), por lo que las manzanas extensas solían tener en el interior de las casas cultivos de pan coger o jardines, emulando a la arquitectura mozárabe en la cual el recinto interno era de notable importancia para la vida doméstica.

Las casas de la década de 1960 a 1970 (en naranja) tenían una constitución distinta, más compacta pero conservaban el antejardín o garaje cuando el uso del automóvil empezó a popularizarse en el barrio. Las manzanas de tamaño mediano tenían edificios angostos pero con un notable espacio interior que suele dividirse en múltiples habitaciones o, incluso, introduciendo bodegas. 


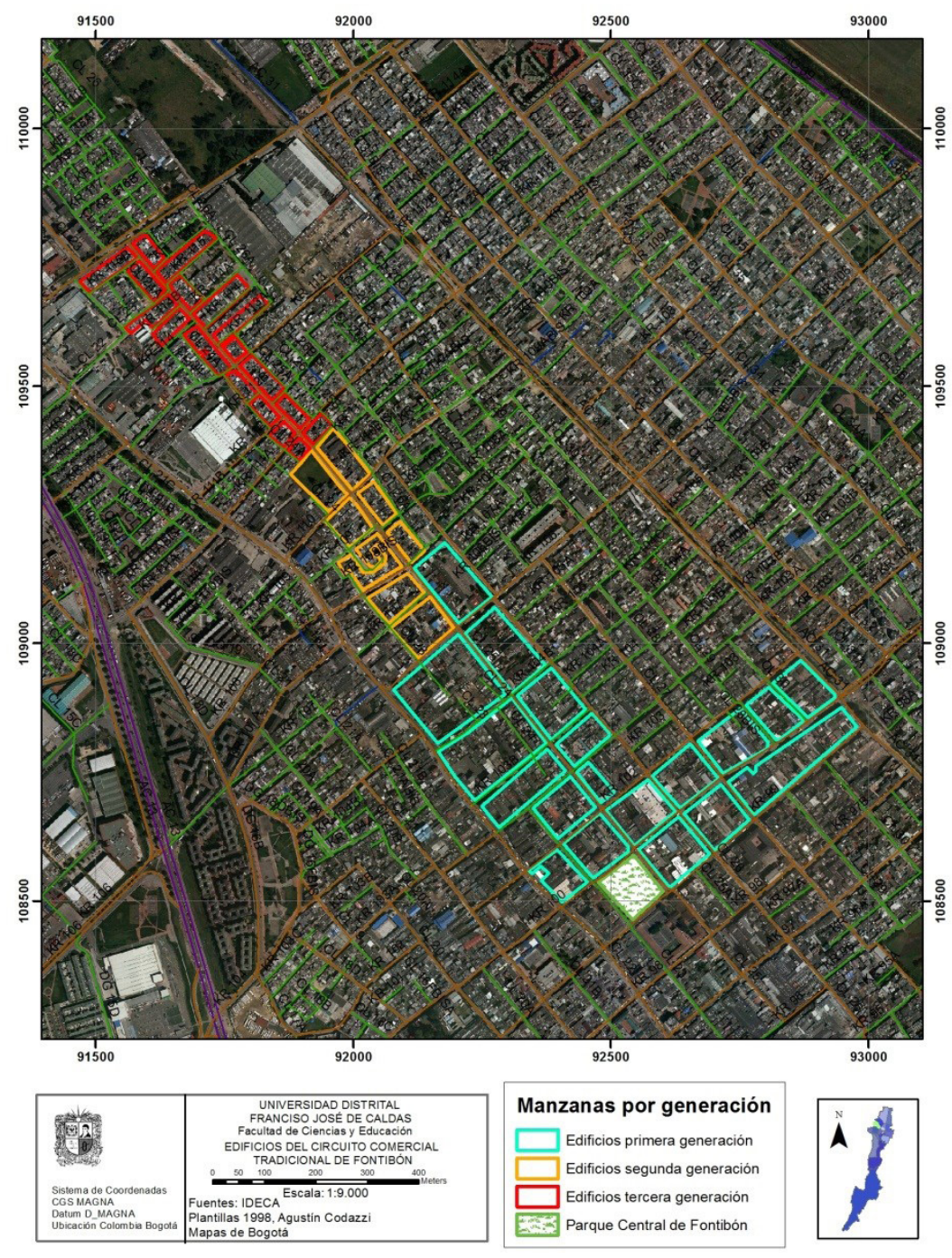

Mapa 1. Manzanas del centro de Fontibón por generaciones

Fuente: creación del autor por medio del SIG Arcgis 10.3, con datos del IGAC, 2009 y del Ideca 2015

Los edificios construidos de 1970 a 1980 (en rojo) son cada vez más disminuidos en extensión para construir verticalmente; las manzanas son de tamaño más reducido que las de sus antecesores pero mantienen la trama original. Muchos de estos barrios de autoconstrucción tienen múltiples divisiones internas y son dedicadas al comercio minorista y a la renta de inquilinatos.
Esta organización espacial determina los alcances del espacio comercial, el cual es una actividad sensible a los cambios dentro del tejido morfológico de la ciudad. Es importante tener en cuenta estas tres generaciones de manzanas que se proyectan desde el centro fundacional para situarse en el siguiente apartado. 


\section{El comercio tradicional y la evolución espacial}

Las necesidades locales han sido satisfechas por las nuevas zonas comerciales que, al igual que en el resto de las localidades de la ciudad, se han ido conformando a medida que negocios del centro se han establecido en ellos o se han formado desde el barrio. A este tipo de consolidación Santos (1996) la denomina circuito comercial tradicional, que es aquel que se ha construido progresivamente con capital local o regional. Dada la capacidad restringida de los capitales invertidos en estos nuevos negocios, su capacidad para transformar el espacio donde se sitúan es limitada, por eso sus formas como negocios están determinadas por la evolución histórico-espacial de la zona y permite oportunidades al igual que niega otras.

Debemos situarnos de nuevo en las generaciones para entender las características que ofrece el comercio según la extensión de las manzanas. La primera generación, tal y como se muestra en el mapa 1 en rojo, tiene los primeros negocios comerciales que se instalaron en el nuevo barrio, además de servicios que en su momento eran muy requeridos, como los teatros.

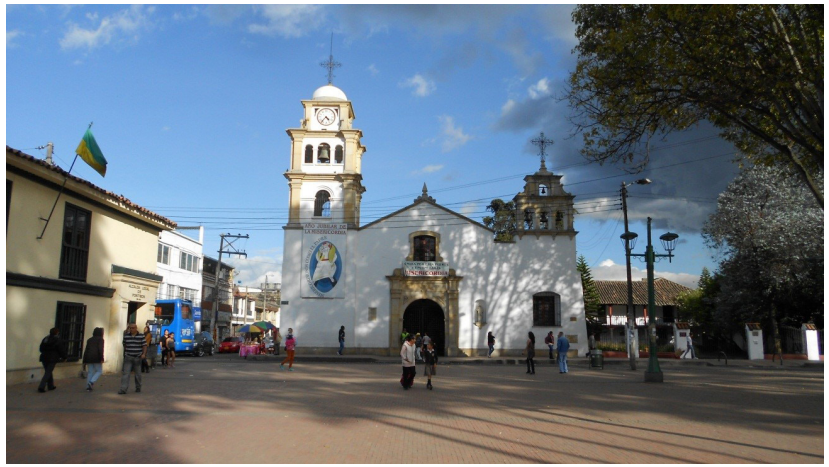

Imagen 1. Iglesia Santiago Apóstol del centro de Fontibón

Los primeros almacenes se establecieron en esta zona, donde pudieron aprovechar el amplio espacio que las manzanas extensas ofrecen; además, se encuentran los pasajes comerciales, los cuales, según Capel (2006), surgieron en Europa en el siglo XIX que siguen siendo construidos en la zona central de Fontibón, acomodados en los espacios extensos que ofrece la zona. Los espacios relativamente extensos permitieron, en un primer momento, la ubicación de edificios comerciales como los pasajes comerciales (imagen 2) en los cuales se conectan calles del barrio y se exponen las mercancías y servicios en vitrinas. Otros, aprovechando la cercanía con el centro de Fontibón que conserva fachadas del período colonial, deciden adaptar sus fachadas como parte de su identidad comercial (imagen 3). los edificios más emblemáticos que son conservados como parte del pasado colonial, evidencia de ello es la iglesia de Santiago Apóstol, la cual es muestra del esfuerzo de la localidad para conservar su pasado municipal.

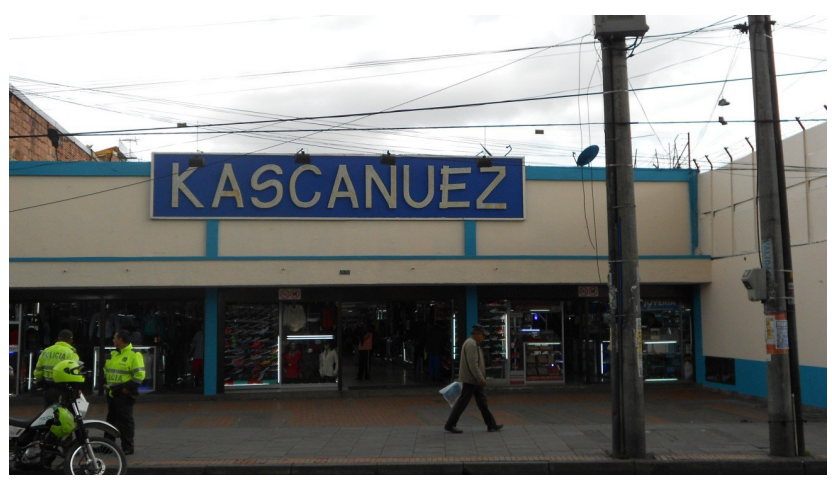

Imagen 2. Pasaje comercial construido en los años noventa dedicado a venta de ropa

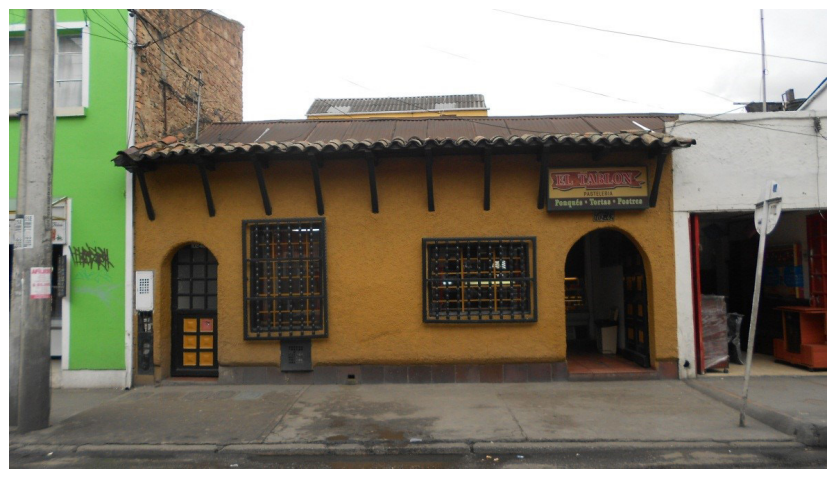

Imagen 3. Restaurante aledaño al centro de Fontibón que adopta forma colonial en su fachada

En la segunda generación, señalada en el mapa 1 en naranja, los negocios tienen menores dimensiones, por el espacio más reducido, por lo que muchos aprovechan intensivamente el espacio con la instalación de uno o más pisos, sin embargo, se localizan edificios con dimensiones considerables (imagen 4). Algunos de los edificios de la segunda generación aprovechan el espacio antes dedicado a antejardines y garajes, lo cual muestra la necesidad de absorber todo el espacio posible para la actividad comercial. 


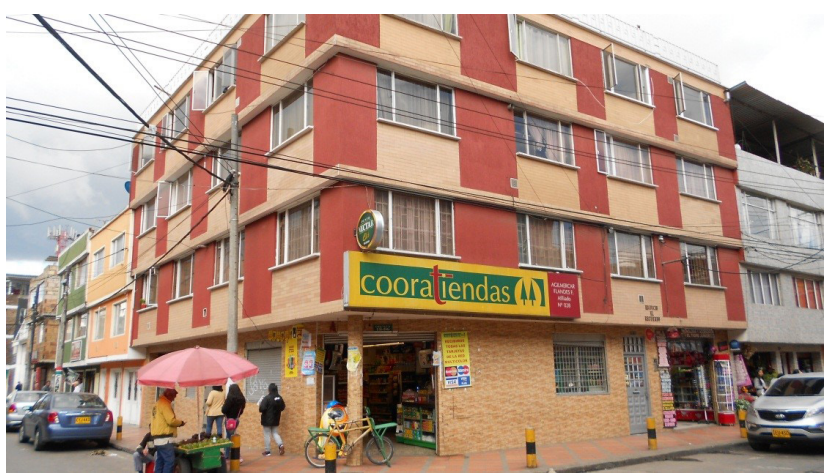

Imagen 4. Edificio comercial y de oficinas

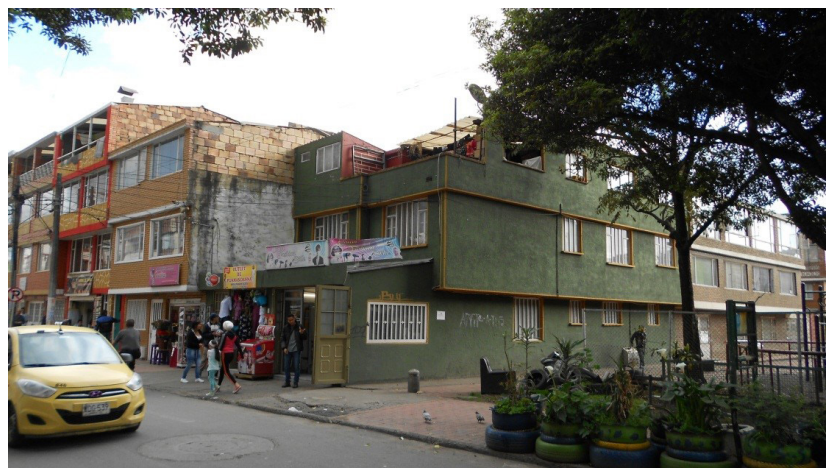

Imagen 5. Vista lateral de una tienda del sector del barrio Batavia

Por otra parte la tercera generación, en rojo en el mapa 1, debido a las manzanas muy compactas los edificios comerciales en su gran mayoría corresponde a tiendas de abarrotes locales y tiendas de variedades, las cuales cuentan con dos pisos en adelante. En la imagen 5 es posible visualizar el tipo de edificios construidos con el interés de aprovechar el terreno urbano de la propiedad cada vez más reducido. Las actividades comerciales se desarrollan paralelamente con actividades complementarias como los alquileres. en la imagen 6 puede verse los edificios de más de tres pisos, debido a la menor disponibilidad del terreno de la propiedad, además de la menor capacidad adquisitiva del propietario, es necesario complementar actividades económicas con rentas de alquileres.

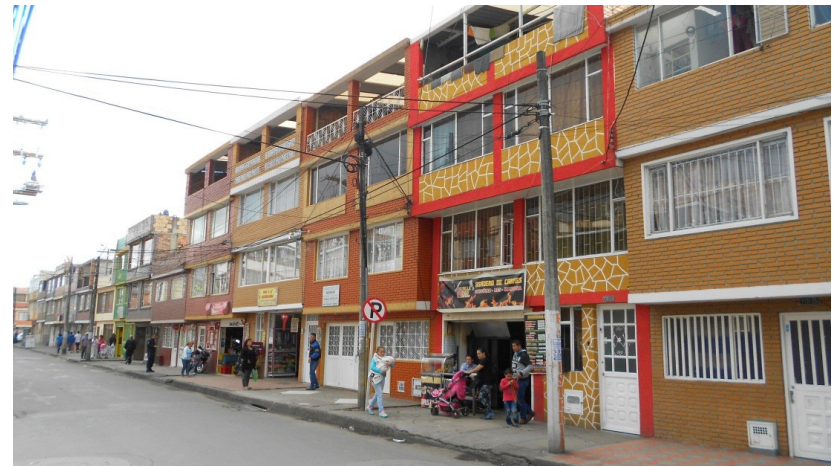

Imagen 6. Edificios del barrio Batavia, que corresponden a la tercera generación, la mayoría con tres pisos en adelante

El comercio depende de la intensidad de resistencia de rugosidad espacial que opone el entramado urbano construido históricamente; mientras que la zona del núcleo fundacional goza de espacios amplios para el desarrollo de sus actividades, el cual puede seguir reconstituyéndose y abriendo espacios para nuevos edificios, la tercera generación tiene negocios dedicados a la subsistencia familiar. Todos estos están sometidos a los avatares del consumo, en los que ciertos servicios son sustituidos por otros, por ejemplo, el antiguo teatro Milán (imagen 7), el cual fue adecuado para dividirlo en locales, la mayoría para venta de artículos electrónicos y software.

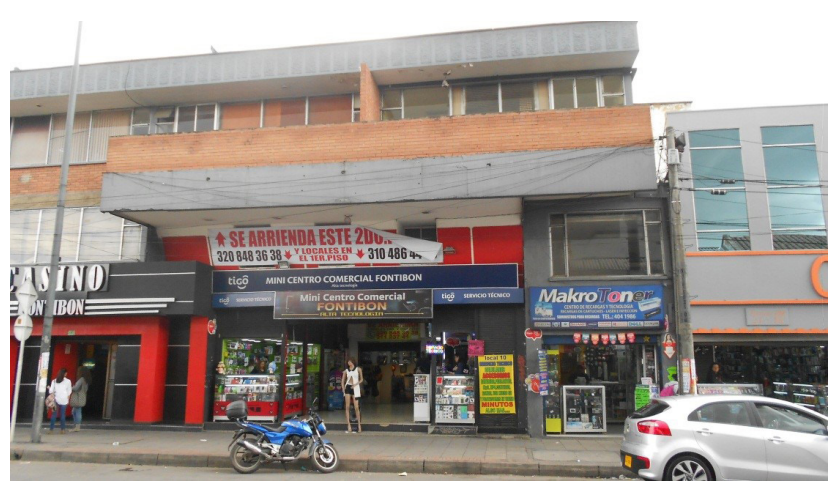

Imagen 7. Antiguo teatro Milán, dedicado en la actualidad a un centro comercial 


\section{Espacios de contacto con el comercio internacional}

En contraste con el desarrollo del espacio comercial que se extiende desde su centro fundacional, en su periferia se han venido instalando formas de comercio distintas, que aprovechan la extensión propia del comercio moderno con tendencia globalizante. Su ubicación fue la propia de antiguas propiedades dedicadas a la agricultura y más tardíamente a la ganadería, por lo que puede considerarse su notable extensión. los espacios comerciales, además de contar con una política económica favorable a su accionar, tienen un capital considerable para modificar la morfología del sector donde se emplazan.

En primer lugar, tenemos el Aeropuerto Internacional El Dorado, el cual fue construido entre los entonces municipios de Engativá y Fontibón, sin contar con el crecimiento que sufrirían ambas localidades hasta el punto de absorberlo dentro de la estructura urbana. Esta estructura es de notable importancia en el intercambio comercial nacional e internacional, por ejemplo, en el envío de productos suntuarios como las flores. Edificada bajo el régimen de Rojas Pinilla, aceleró el proceso de conurbación de Fontibón a la ciudad y, según Cortez (2006), implicó también el fin de todo esfuerzo de planificación para organizar el futuro crecimiento de la ciudad, pues las estructuras mastodónticas son invasivas e iban en completa contravía de los estudios realizados por los urbanistas Brunner y Le Corbusier.

En segundo lugar, la Zona Franca de Bogotá, ubicada en la vía Bogotá-Mosquera, tiene un emplazamiento de gran importancia al conectarse con la vía en dirección al occidente del país, específicamente con el puerto de Buenaventura, con su cercanía al Aeropuerto Internacional El Dorado, que se ha mencionado, y con la zona industrial de Fontibón y Puente Aranda. La infraestructura y el acceso vial es de considerable calidad, con un mantenimiento y redes viales muy completas para beneficio de las empresas afiliadas, además de tener su propio sistema de alimentación de energía, amplios aparcamientos y edificios de oficinas para gestión empresarial internacional.

La Zona Franca tiene a su disposición una legislación igualmente favorable para su desenvolvimiento: la Ley 1004 del 2005, además de un conglomerado legislativo apoyado en la Constitución de 1991 para ser un lugar privilegiado para el comercio internacional y la instalación industrial. Su conexión internacional privilegiada contrasta con la conexión con su intercambio local, el cual no se ha visto beneficiado pese a que uno de sus principios fundadores es la responsabilidad social.

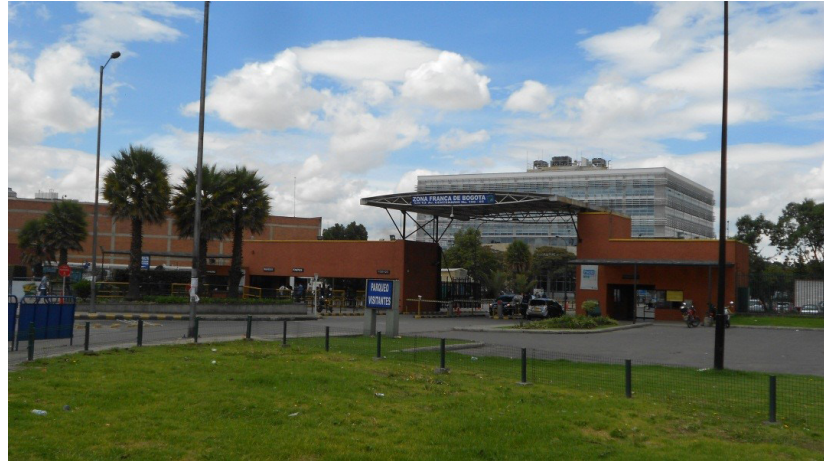

Imagen 8. Acceso oriental a la Zona Franca de Bogotá

En tercer lugar, cercano a la Zona Franca el nuevo centro comercial del Éxito ${ }^{\oplus}$ se ha establecido en el vecindario, ofreciendo una gran cantidad de servicios que el sector no puede dar, dado que la mayor parte son apartamentos y urbanizaciones cuyo origen es de interés social. Este tipo de centro comercial tiene un interés monopólico al concentrar todas las actividades de comercio en un único núcleo, con el consiguiente debilitamiento del comercio local que le precede (Castells, 2006). Un sistema similar es el Sambil en Venezuela: grandes centros comerciales construidos en la periferia donde grandes conjuntos residenciales son abastecidos, comercio dirigido a las clases altas, ajenas a la dinámica del barrio y todas sus problemáticas de contaminación, delincuencia, pobreza y mendicidad muy acorde a la ideología neoliberal (Amaya, 2009). En el caso del Éxito, va dirigido a clases medias y bajas, dado que parte de las construcciones, como Sabana Grande y Pueblo Nuevo, fueron hechas como viviendas de interés social, pero cerca a esta estructura y en su interior se concentran servicios de salud, educación básica, oficinas bancarias, correspondencia, restaurantes, incluso una parroquia.

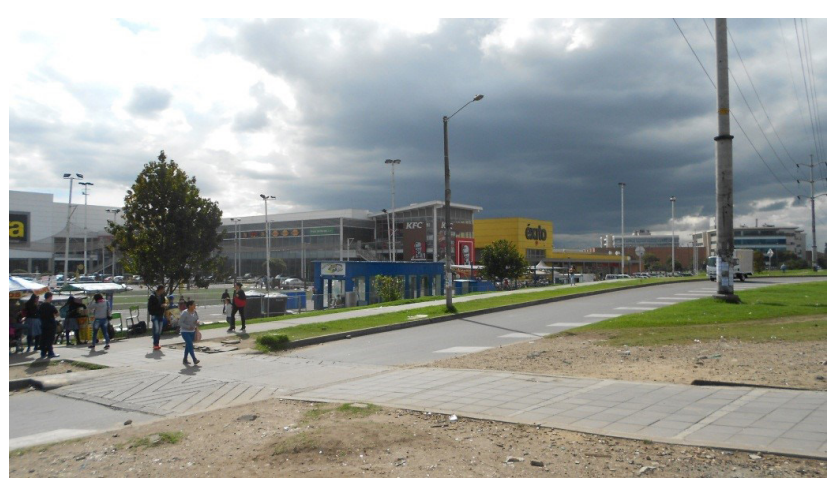

Imagen 9. Éxito de Fontibón 
En su conjunto, estas estructuras de comercio han modificado la morfología periférica del barrio. Son construcciones que cuentan con abundante capital de inversión, ventajas en infraestructura pública, construcción homogénea prefabricada de forma industrial, beneficios tributarios y un espacio que no opone la resistencia histórico-espacial que la rugosidad del barrio que carece de la mayoría de estos mecanismos, tiene un capital limitado al nacional, una infraestructura pública sobrecargada y sometida a un crecimiento desbocado por la instalación de vendedores informales en la vía pública, causado, entre otras cuestiones, por la incapacidad del sector industrial para absorber a este conjunto de potenciales trabajadores. Esta diferencia fundamental hace que ambos espacios permanezcan aislados, los comercios modernos de la periferia mantienen sistemas de seguridad que los aíslan de su entorno para no permearse de los problemas y mantener sus dispositivos de control y funcionamiento internos sin distorsiones.

\section{¿Comercio local vs. comercio global?}

La distinción entre espacio comercial local y global había sido realizada por Santos (1973) como circuito económico tradicional y circuito económico moderno, incluso con una acepción propia para el espacio de globalización. La diferencia que establece en ambos es la tecnológica y de capital, siendo el espacio de globalización un espacio técnico-científico donde la zona es homogeneizada en función de la eficiencia tanto en el tiempo de construcción como en la capacidad interna de transporte, seguridad y comunicaciones. Mientras el espacio de comercio tradicional absorbe la mayor parte de las contradicciones sociales que se desarrollan en la sociedad, entre ellas la de venta informal, que se ha instalado en calles adyacentes ante el conflicto con los comerciantes y las autoridades que los relegaron de la carrera 100.

La falta de comunicación entre ambas es otra de las características esenciales del circuito comercial moderno en relación con el del circuito comercial tradicional, una situación que lleva a un mutuo aislamiento que segrega de las oportunidades que espacios comerciales podrían ofrecer, especialmente el de la Zona Franca, dado que menos del $14 \%$ de las empresas dedicadas al sector de importación y exportación (CCB, 2006) priva por esta relación limitada de las pequeñas y medianas empresas de beneficiarse del mercado internacional.Esta desarticulación lleva a que el comercio tradicional se vea sometido a los vaivenes del consumo y que su nivel de liquidación sea elevado, pues alrededor de un $85 \%$ de las empresas liquidadas en Bogotá pertenece al sector de comercio y servicios, debido a la inexperiencia, al capital reducido con el que inician y los problemas administrativos internos que provocan su disolución (CCB, 2009).
La vulnerabilidad del circuito comercial tradicional es mucho mayor en comparación al de las grandes empresas del comercio con conexión global. En el caso de la Zona Franca, el capital mínimo para involucrarse es de 500 millones, mientras que las microempresas que suelen iniciar los negocios del barrio lo hacen con 6 millones (CCB, 2009). Por esta razón, la capacidad del negocio comercial del circuito tradicional debe adaptarse al entramado histórico-espacial que Fontibón le ofrece. Su capacidad para transformarlo es muy reducida y se limita a la organización en el interior del establecimiento y los servicios ofrecidos.

Esto resulta ser un desequilibrio entre la ciudad históricamente desarrollada y los injertos comerciales-industriales, como en el caso de la Zona Franca de Bogotá, un espacio establecido allí donde la resistencia espacial fuera menor y, a su vez, se pusieran a su servicio unos privilegios económicos y de infraestructura que incluso lo aíslan del entorno barrial, el cual debería ser beneficiario, por lo menos, de forma indirecta. Los injertos comerciales traen consigo unos procesos estandarizados y una importación de maquinaria que no necesariamente es sinónimo de desarrollo, sino más bien de dependencia a los productos industriales producidos en los países desarrollados (Santos, 1973).

Esto lleva a una serie de reflexiones, dada la proliferación de zonas francas como espacios de articulación de los mercados del Caribe para solventar sus propias falencias en competitividad, que les impiden atraer inversión extranjera, además de los grandes centros comerciales que se ubican en espacios urbanos homogéneos y que son lugares cooptados por el gran capital y que inhiben el crecimiento de otros tipos de negocios que se desarrollarían armónicamente con el barrio progresivamente. La primera preocupación es sobre los procesos urbanos mastodónticos y su pertinencia, que critica Capel (2006), sobre la sobrecarga de autopistas y la insuficiencia de los grandes centros comerciales de proveer todos los servicios y productos de los suburbios, los cual además, según Jacobs (1961), deja amplios espacios apartados de la dinámica del barrio que, en cierta manera, acoge al ciudadano transeúnte y le ofrece un espacio de sentido.

La segunda preocupación es si estos espacios son de alguna forma inevitables a corto y mediano plazo ante la legislación y la política económica aperturista al comercio internacional, ¿no es necesario igualmente articular el espacio comercial tradicional a las ventajas de estas nuevas dinámicas de las cuales permanece ajeno? Queda claro que el renglón de la economía del sector de comercio y servicios vive una creciente diversificación ante la reducción de la industria en su asimilación de mano de obra, pero ¿estará dicha asimilación condenada a la diversificación dentro de la precariedad y el abandono estatal? 


\section{Referencias}

Amaya, C. (2009). Rol de los centros comerciales en la organización espacial de las principales aglomeraciones urbanas de Venezuela. Revista geográfica venezolana, 50(2), 263-286.

Brewer-Carías, A. (2006). La ciudad ordenada. Caracas: Criteria.

Capel, H. (2006). La morfología de las ciudades, vol. II Aedes Facere: técnica, cultura y clase social en la construcción de edificios Barcelona: Del Serbal.

Cámara de Comercio de Bogotá (2006). Perfil económico y empresarial, localidad de Fontibón. John Wilson Buitrago (coord.). Bogotá: Imprenta Distrital.

Cámara de Comercio de Bogotá (2009). Brechas de competitividad de Bogotá, en el contexto de América Latina. Bogotá: Imprenta Distrital.

Cámara de Comercio de Bogotá -CCB- (2009). Informe sobre las causas de la liquidación de las empresas en Bogotá. Bogotá: Horizontes Gráficos.

Capel, H. (2006). La morfología de las ciudades, vol. II Aedes Facere: técnica, cultura y clase social en la construcción de edificios. Barcelona: Del Serbal.

Garavaglia, J. y Marchena J. (2005). América Latina de los orígenes a la independencia, América precolombina y la consolidación del espacio colonial. Barcelona: Grupo Planeta.

Jacobs, J. (1961). Muerte y vida de las grandes ciudades. Madrid: Capitán Swing.

Ley 1004 del 2005 (30 de diciembre). por la cual se modifican un régimen especial para estimular la inversión y se dictan otras disposiciones. Diario Oficial $n .^{\circ} 46.138$.

Velandia, R. (1983). Fontibón, Pueblo de la Real Corona. Bogotá: Imprenta Distrital. 